\title{
Observations on the feeding behaviour of parasitic third- stage hookworm larvae
}

\author{
J. M. HAWDON ${ }^{1 *}$, S. W. VOLK ${ }^{1}$, R. ROSE ${ }^{2}$, D. I. PRITCHAR ${ }^{2}$, J. M. BEHNKE ${ }^{2}$ \\ and $\mathrm{G}$. A. SCHAD \\ ${ }^{1}$ Department of Pathobiology, University of Pennsylvania, Philadelphia, PA, USA \\ ${ }^{2}$ Department of Zoology, University of Nottingham, Nottingham, UK
}

(Received 22 April 1992 ; revised 17 fuly 1992 ; accepted 17 fuly 1992)

SUMMARY

The feeding behaviour of parasitic 3rd-stage larvae $\left(\mathrm{L}_{3}\right)$ of the hookworms Ancylostoma caninum, A. ceylanicum and Necator americanus was examined. Less than $11 \%$ of $A$. caninum $\mathrm{L}_{3}$ recovered from the small intestines of dogs infected orally were feeding at $4-48 \mathrm{~h}$ post-infection (p.i.), and none of the $A$. ceylanicum $\mathrm{L}_{3}$ recovered from the intestines of orally infected hamsters had resumed feeding. All $\mathrm{L}_{4}$ of both species recovered at 36 and $48 \mathrm{~h}$ p.i. had resumed feeding. On the other hand, approximately $16 \%$ of the $A$. ceylanicum $\mathrm{L}_{3}$ recovered from the skin of percutaneously infected hamsters at $18 \mathrm{~h}$ were feeding, and the percentage feeding increased to nearly $58 \%$ at $44 \mathrm{~h}$ p.i. Necator americanus $\mathrm{L}_{3}$ recovered from the skin of percutaneously infected neonatal hamsters resumed feeding at $6-12 \mathrm{~h}$ p.i. and reached $90-94 \%$ by $18 \mathrm{~h}$. Feeding began to decline at $66 \mathrm{~h}$, and reached $29 \%$ at $120 \mathrm{~h}$ p.i. This decrease was associated with the migration of larvae from the skin to the lungs. By $192 \mathrm{~h}$ p.i. over $95 \%$ of the larvae had reached the small intestine, and all had moulted to the $\mathrm{L}_{4}$. The results indicate that parasitic $\mathrm{L}_{3}$ resume feeding in the skin during percutaneous infections, and suggest that feeding by hookworm $\mathrm{L}_{3}$ correlates with the resumption of development.

Key words : Ancylostoma caninum, Ancylostoma ceylanicum, Necator americanus, hookworms, resumption of development, in vitro feeding.

\section{INTRODUCTION}

The behaviour of infective larvae of hookworms following entry into the host has been an area of long-standing research. Most of this research was conducted using the canine hookworm Ancylostoma caninum and, consequently, the migratory behaviour of $A$. caninum larvae in the dog and abnormal hosts following oral and percutaneous infections is relatively well defined (Scott, 1930; Foster \& Cross, 1934; Banerjee, Prakash \& Deo, 1970; Miller, 1971; Bhopale \& Johri, 1975). More recently, the hookworms that infect man have been adapted to laboratory hosts (Ray and Bhopale, 1972; Sen, 1972; Schad, 1979), enabling studies of hookworm biology in models that, although not the usual definitive host, permit completion of their life-history (Behnke, 1990). Investigations of host-parasite interaction and the behaviour of human hookworm infective larvae during the early parasitic stages are now possible (Rajasekariah et al. 1985; Behnke, Paul \& Rajasekariah, 1986a; Behnke \& Pritchard, 1987; Gupta, Srivastava \& Katiyar, 1987; Garside \& Behnke, 1989).

Despite these advances, many aspects of the early parasitic portion of the hookworm life-history remain unknown. For example, the time at which

* Present address: Yale University School of Medicine, 501 LEPH, New Haven, CT 06510, USA. invading larvae resume feeding is poorly understood. Hawdon \& Schad (1990) suggested that larval feeding represents an initial event in the transition to the parasitic life-style, and have proposed that the resumption of feeding can be used as a marker for the reactivation of development in $A$. caninum $3 \mathrm{rd}$-stage larvae. Subsequent experiments indicated that infective larvae of several hookworm species, including $A$. duodenale and $A$. ceylanicum, resumed feeding in vitro (Hawdon et al. 1992). The investigations reported herein were undertaken to determine the role of larval feeding in the life-history of hookworms.

\section{MATERIALS AND METHODS}

Ancylostoma caninum and $A$. duodenale were maintained in dogs as described previously (Schad, 1979, 1982). Necator americanus (Behnke, Wells \& Brown, $1986 b$ ) and A. ceylanicum (Garside \& Behnke, 1989) were maintained in hamsters. Infective larvae were harvested from 7 to 14-day coprocultures and stored in nematode handling buffer (BU; $50 \mathrm{~mm}$ $\mathrm{Na}_{2} \mathrm{HPO}_{4} / 22 \mathrm{~mm} \mathrm{KH}_{2} \mathrm{PO}_{4} / 70 \mathrm{~mm} \mathrm{NaCl}, \mathrm{pH} 6 \cdot 8$ ) until needed (1-14 days). Storage under these conditions had no effect on subsequent feeding (Hawdon \& Schad, 1991 a).

Feeding was determined by the method of Hawdon \& Schad (1990), with slight modifications. $\mathrm{L}_{3}$ recovered from tissues were resuspended in approx- 
imately $0.1 \mathrm{ml}$ of medium and transferred to individual wells of a 96 -well tissue culture plate. An equal volume of $5 \mathrm{mg} / \mathrm{ml}$ fluorescein isothiocyanatelabelled bovine serum albumin (FITC-BSA) was added, and the larvae incubated at $37^{\circ} \mathrm{C}, 5 \% \mathrm{CO}_{2}$ for 1-2 h. After incubation, the $\mathrm{L}_{3}$ were washed in

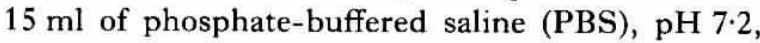
transferred to a microscope slide, and examined under ultra-violet illumination. Feeding larvae, indicated by the presence of dye in the intestine, were counted and the number expressed as a percentage of the total number of larvae counted.

Experiment 1 was designed to determine when A. caninum $\mathrm{L}_{3}$ resumed feeding in dogs infected per os. Ten 12-week-old helminth-naive beagles were divided into 5 groups of 2 each, and each pair inoculated orally with $5000 \mathrm{~A}$. caninum $\mathrm{L}_{3}$ in gelatin capsules. Several of the dogs regurgitated following inoculation. In these cases, the vomitus was recovered, mixed with cottage cheese, and refed to the $\mathrm{dog}$. In one case ( $4 \mathrm{~h}$ post-infection), the dogs were sedated and the vomitus given via stomach tube. Subsequent recovery of larvae in these cases was lower than from animals that had not vomited.

After the appropriate time, the dogs were killed by barbiturate overdose, and the small intestine removed (the stomach was also examined in the $4 \mathrm{~h}$ time-point). Each intestine was opened longitudinally, and cut into $3-4$ sections. The sections were hung for $2-3 \mathrm{~h}$ in 21 cylinders containing PBS at $37^{\circ} \mathrm{C}$. After the incubation, the intestines were removed, and the sediments collected and concentrated. Dilution counts of the sediments were done to determine the number of larvae recovered, and 150-200 larvae were individually picked from the sediments, washed 3-4 times in $15 \mathrm{ml}$ of RPMI tissue culture medium and assayed for feeding. The larvae recovered from each animal served as a replicate.

Experiment 2 was a similar experiment using hamsters inoculated orally with $A$. ceylanicum $\mathrm{L}_{3}$. Six groups of 5 weanling $\mathrm{LVG}$ hamsters (Charles River Labs, Willmington, Massachusetts) were inoculated with approximately $500 \mathrm{~A}$. ceylanicum $\mathrm{L}_{3}$ in $0.1 \mathrm{ml}$ by gastric gavage using a curved feeding needle attached to a $1 \mathrm{ml}$ syringe. At the appropriate time post-infection (p.i.), the hamsters were killed by chloroform inhalation, and the small intestines removed. The intestinal lumina were rinsed with PBS, and the intestines opened longitudinally, then cut into approximately $1 \mathrm{~cm}$ pieces. The lumen wash and intestinal pieces from each hamster were subjected to the Baermann technique in PBS at $37^{\circ} \mathrm{C}$, $5 \% \quad \mathrm{CO}_{2}$ for $1 \mathrm{~h}$. Recovered $\mathrm{L}_{3}$ were washed by centrifugation $(1000 \mathrm{~g}) 3$ times in $15 \mathrm{ml}$ of PBS, followed by 2 washes in RPMI tissue culture medium. The larvae were assayed for feeding as described above.
Because of the expense and difficulty in isolating sufficient numbers of percutaneously infected $\mathrm{L}_{3}$ from dogs, the feeding behaviour of skin-penetrating larvae was examined using the hamsterA. ceylanicum model. Groups of $2-3$ adult hamsters were inoculated percutaneously with $200-2500 \mathrm{~L}_{3}$ A. ceylanicum by the method of Behnke et al. (1986 b) with slight modification. Hamsters were lightly anaesthetized by Halothane inhalation and their abdomen and back shaved. Larvae in $0.1 \mathrm{ml}$ of water were applied to the pad on a 1 inch adhesive bandage (Curad), and the bandage affixed to the abdominal surface of the hamster. The bandage was secured with surgical tape wrapped around the abdomen. At the appropriate time-point, the hamsters were killed and the bandages removed. The infection site skin, underlying muscle, lungs and intestine were removed, minced and incubated in individual Petri dishes at $37^{\circ} \mathrm{C}, 5 \% \mathrm{CO}_{2}$ for $4 \mathrm{~h}$. After incubation, $\mathrm{L}_{3}$ were counted and individually picked into microfuge tubes. The larvae were washed in RPMI, resuspended in $0 \cdot 1 \mathrm{ml}$ of medium, and transferred to a tissue culture plate for the feeding assay. Because of poor recovery at the $18 \mathrm{~h}$ time-point, the larvae recovered from 2 hamsters were pooled for feeding, and therefore each replicate at this time-point is derived from a separate experiment.

The feeding behaviour of $N$. americanus $\mathrm{L}_{3}$ during percutaneous infection was also examined. $N$. americanus $\mathrm{L}_{3}$ are obligate skin penetrators, and infection is established by percutaneous inoculation of 2 to 4 day-old hamster pups (Sen \& Seth, 1970; Sen, 1972; Behnke, Wells \& Brown, 1986). Therefore, the number of animals available for infection depends on litter size and mortality of the pups prior to infection, but a minimum of 2 pups were used per time-point. Hamsters were either bred on site, or purchased as timed-pregnant adults. Neonates were infected with approximately $1000 \mathrm{~L}_{3}$ by the method of Behnke et al. $(1986 b)$. At the appropriate time, the pups were killed by decapitation, and the skin, lungs, and intestines removed to individual Petri dishes. The tissue was minced and incubated in RPMI medium for 2-3 h. $\mathrm{L}_{3}$ were counted and picked to individual tubes, washed with RPMI, and assayed for feeding. The larvae recovered from each hamster represent 1 replicate in the feeding experiments, and between 40 and 140 total $\mathrm{L}_{3}$ were examined per replicate, depending on the number of $\mathrm{L}_{3}$ recovered.

Feeding data (percentages) were transformed to angular values by arcsin transformation. One-way ANOVA was performed on the transformed data, and the means compared using the Bonferroni posttest; $P<0.05$ was considered significant. Mean angular values were transformed back to percentages for expression. 


\section{RESULTS}

Recovery of $\mathrm{L}_{3}$ A. caninum from orally inoculated dogs ranged from 2 to $56 \%$. Recovery was lower from dogs that had vomited the inoculum, ranging from 2 to $28 \%$, whereas recovery ranged from 45 to $56 \%$ in dogs that retained the inoculum. All of the larvae recovered were exsheathed.

As seen from the data presented in Table 1, A. caninum $\mathrm{L}_{3}$ were feeding at low levels from 4 to $24 \mathrm{~h}$ post-infection. The percentage of $\mathrm{L}_{3}$ that were feeding reached a maximum of $10 \cdot 3 \pm 5 \cdot 6 \%$ by $24 \mathrm{~h}$, after which time it dropped to $0 \%$ at $36 \mathrm{~h}$. At this time, $1.5 \%(3 / 200)$ of the larvae examined for feeding were 4 th-stage larvae $\left(\mathrm{L}_{4}\right)$, whereas $64.0 \%$ $(137 / 214)$ of larvae examined at $48 \mathrm{~h}$ were $L_{4}$, indicating that larval development had resumed. The mean increase in feeding at $48 \mathrm{~h}$ was caused by the $\mathrm{L}_{4}$, which had resumed feeding (Table 1).
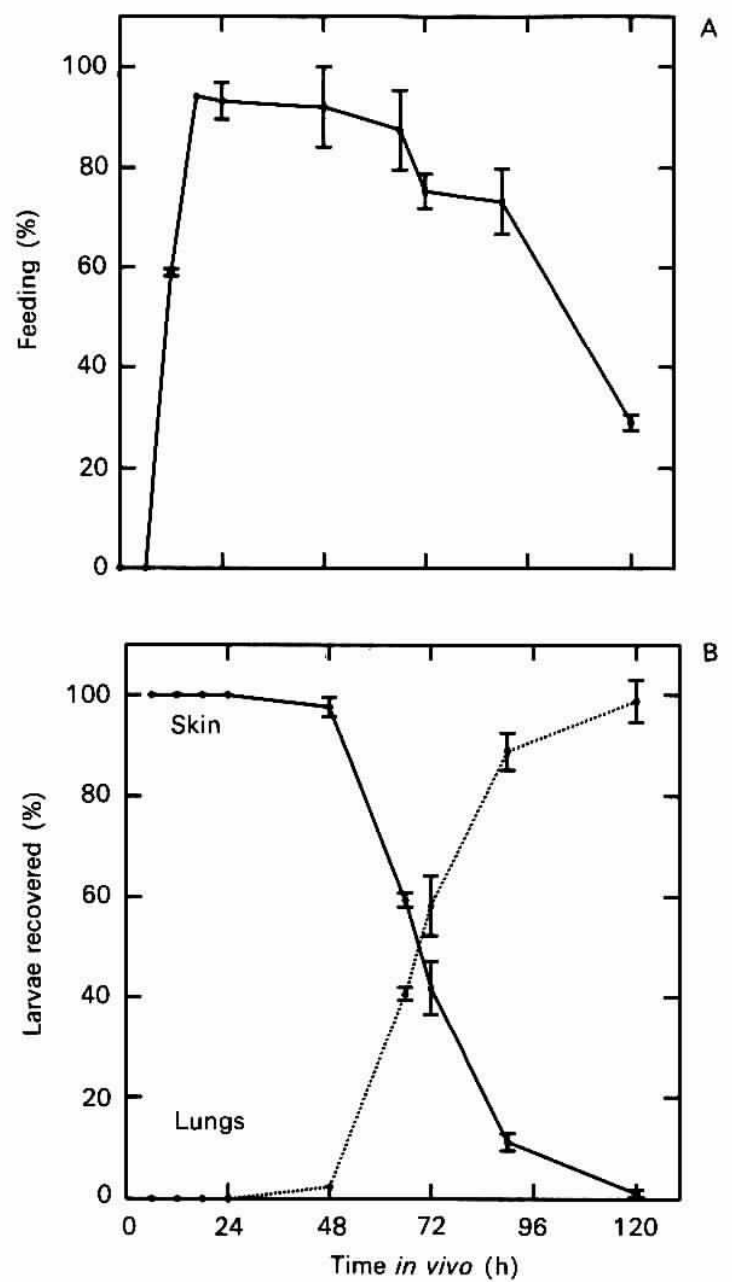

Fig. 1. Feeding behaviour and recovery of Necator americanus larvae from percutaneously infected neonatal hamsters. (A) Feeding. Each point represents the mean feeding \pm S.D. of the larvae recovered from a minimum of 2 hamsters. (B) Graphical representation of tissuespecific recovery data presented in Table 3.
Table 1. Feeding by Ancylostoma canimum larval stages recovered from orally infected dogs

\begin{tabular}{lllll}
\hline \hline $\begin{array}{l}\text { Time } \\
\text { p.i. } \\
\text { (h) }\end{array}$ & Dog & $\begin{array}{l}\mathrm{L}_{3} \text { feeding* } \\
(\%)\end{array}$ & $\begin{array}{l}\mathrm{L}_{4} \text { feeding } \\
(\%)\end{array}$ & $\begin{array}{l}\text { Mean } \\
\text { percentage } \\
\text { feeding }\end{array}$ \\
\hline 4 & P3 & $4(3 / 85)$ & N.R.† & \\
& L6 & $0(0 / 79)$ & N.R. & $1 \cdot 0 \pm 1 \cdot 4$ \\
12 & T5 & $0(0 / 100)$ & N.R. & $2 \cdot 8 \pm 4 \cdot 0$ \\
& P4 & $11(3 / 27)$ & N.R. & \\
24 & J3 & $4(3 / 81)$ & N.R. & $10 \cdot 3 \pm 5 \cdot 6$ \\
& P2 & $19(7 / 37)$ & N.R. & \\
36 & T4 & $0(0 / 100)$ & N.R. & $0 \cdot 8 \pm 1 \cdot 1$ \\
& R4 & $0(0 / 97)$ & $100(3 / 3)$ & \\
48 & J4 & $0(0 / 29)$ & $100(85 / 85)$ & \\
& P5 & $2(1 / 48)$ & $100(52 / 52)$ & $64 \cdot 4 \pm 11 \cdot 3$ \\
\hline \hline
\end{tabular}

* (Number feeding/total number examined.) + N.R., None recovered.

Table 2. Feeding by Ancylostoma ceylanicum 3rdstage larvae recovered from percutaneously infected hamsters

\begin{tabular}{llll}
\hline \hline $\begin{array}{l}\text { Time p.i. } \\
\text { (h) }\end{array}$ & Replicate & $\begin{array}{l}\text { Percentage } \\
\text { feeding }\end{array}$ & $\begin{array}{l}\text { Mean } \\
\text { percentage } \\
\text { feeding } \pm \text { s.D. }\end{array}$ \\
\hline 18 & 1 & $15 \cdot 8(15 / 95)^{*}$ & \\
& 2 & $15 \cdot 6(5 / 32)^{*}$ & $15 \cdot 7 \pm 0 \cdot 7$ \\
24 & 1 & $46 \cdot 1(41 / 89)$ & \\
& 2 & $46 \cdot 4(32 / 69)$ & $46 \cdot 3 \pm 0 \cdot 1$ \\
44 & 1 & $65 \cdot 0(65 / 100)$ & \\
& 2 & $50 \cdot 0(8 / 16)$ & $57 \cdot 6 \pm 7 \cdot 2$ \\
\hline \hline
\end{tabular}

* Larvae recovered from 2 hamsters were pooled for feeding.

Table 3. Total and tissue-specific recovery of Necator americanus larvae from percutaneously infected neonatal hamsters

\begin{tabular}{lllll}
\hline \hline & & \multicolumn{3}{c}{$\begin{array}{l}\text { Mean percentage of } \\
\text { recovered larvae from: }\end{array}$} \\
\cline { 3 - 5 } $\begin{array}{l}\text { Time } \\
\text { p.i. } \\
\text { (h) }\end{array}$ & $\begin{array}{l}\text { Percentage } \\
\text { of dose } \\
\text { recovered* }\end{array}$ & Skin & Lungs & $\begin{array}{l}\text { Small } \\
\text { intestine }\end{array}$ \\
\hline 6 & $30 \cdot 8 \pm 4 \cdot 4$ & 100 & N.D. & N.D. \\
12 & $48 \cdot 5 \pm 0 \cdot 6$ & 100 & N.D. & N.D. \\
18 & $49 \cdot 3 \pm 1 \cdot 5$ & 100 & 0 & 0 \\
24 & $39 \cdot 0 \pm 4 \cdot 8$ & 100 & 0 & 0 \\
48 & $43 \cdot 3 \pm 1 \cdot 1$ & $97 \cdot 6$ & $2 \cdot 4$ & 0 \\
66 & $40 \cdot 3 \pm 12 \cdot 8 \dagger$ & $59 \cdot 4$ & $40 \cdot 6$ & 0 \\
72 & $43 \cdot 3 \pm 0 \cdot 5$ & $44 \cdot 8$ & $58 \cdot 2$ & 0 \\
90 & $47 \cdot 4 \pm 2 \cdot 7$ & $11 \cdot 2$ & $88 \cdot 8$ & 0 \\
120 & $53 \cdot 7 \pm 5 \cdot 7$ & $1 \cdot 2$ & $98 \cdot 8$ & 0 \\
192 & $12 \cdot 6 \pm 4 \cdot 1$ & 0 & 4.1 & 95.9 \\
\hline \hline
\end{tabular}

${ }^{*}$ Mean $\%, n=3 ; n=2$ for 18,66 and $120 \mathrm{~h} ; n=4$ for $192 \mathrm{~h}$.

† A portion of inoculum was lost during infection. N.D, Not determined. 


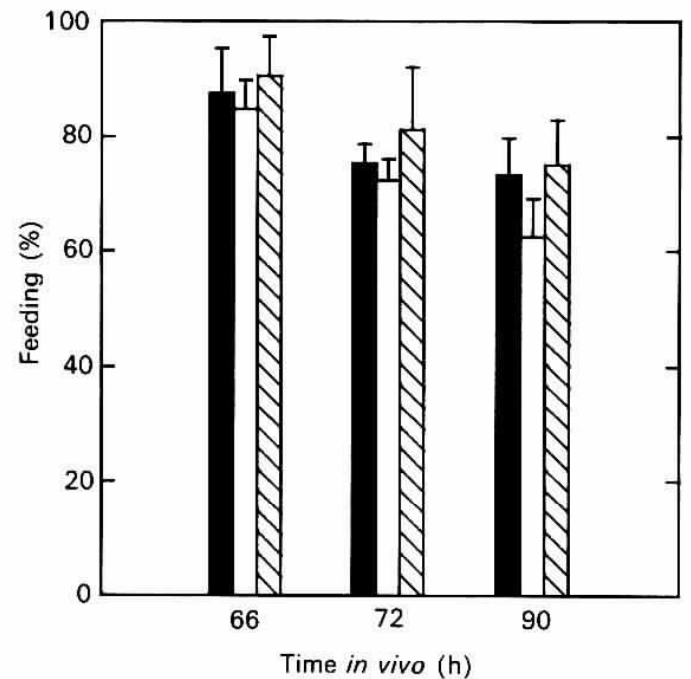

Fig. 2. Percentage feeding of Necator americanus $\mathrm{L}_{3}$ recovered from skin and lungs of neonatal hamsters at $66,72$ and $90 \mathrm{~h}$ post-infection. ( $\square)$ Total; $(\square)$ skin $\mathrm{L}_{3}$; (\$) lung $\mathrm{L}_{3}$.

None of the $\mathrm{L}_{3}$ recovered at any time-point from hamsters infected with $A$. ceylanicum per os had resumed feeding, whereas all of the $\mathrm{L}_{4}$ recovered were feeding. At $36 \mathrm{~h}, 1 \%$ of the larvae examined were $\mathrm{L}_{4}$, whereas by $48 \mathrm{~h}$, the number of $\mathrm{L}_{4}$ increased to $9 \%$ of the examined larvae.

The feeding behaviour of $\mathrm{L}_{3}$ from a percutaneously initiated infection was examined using A. ceylanicum $\mathrm{L}_{3}$. As shown in Table 2, 15.7 $\pm 0.7 \%$ of the $\mathrm{L}_{3}$ isolated from the skin of percutaneously infected hamsters had resumed feeding by $18 \mathrm{~h}$. The percentage feeding increased to $57 \cdot 6 \pm 7 \cdot 2 \%$ at $44 \mathrm{~h}$. No larvae were recovered from any of the tissues examined other than those of the infection site skin and underlying muscle. Recovery of larvae was variable, ranging from 2 to $23 \%$. The decreased efficiency of infection by the percutaneous route (Gupta et al. 1987) undoubtedly accounts for the low recovery rates. The $\mathrm{L}_{3}$ had exsheathed, but there was no morphological evidence of further development, although percutaneously infected control hamsters developed patent infections within 3 weeks p.i., confirming that skin penetration is a viable route of entry for $A$. ceylanicum $\mathrm{L}_{3}$.

$N$. americanus $\mathrm{L}_{3}$ recovered from percutaneously infected neonatal hamsters resumed feeding 6-12 h p.i., and reached a maximum percentage feeding, at $90-94 \%$, by $18 \mathrm{~h}$ (Fig. 1A). Feeding remained at this high level until $66 \mathrm{~h}$, when the percentage feeding began to decline. This decline coincided with decreased recovery of larvae from the skin, and increased recovery from the lungs (compare Fig. 1A and B). Feeding decreased to $29.0 \pm 1.6 \%$ at $120 \mathrm{~h}$, when $98 \cdot 8 \pm 4 \cdot 2 \%$ of the recovered $\mathrm{L}_{4}$ were from the lungs. At $192 \mathrm{~h}$ p.i., all of the recovered larvae were $\mathrm{L}_{4}$ and had resumed feeding. The overall recovery had dropped from approximately $50 \%$ at $120 \mathrm{~h}$ to $12.6 \%$ at $192 \mathrm{~h}, 95.9 \% \pm 10.2 \%$ of which were recovered from the small intestine (Table 3 ). This decreased recovery was seen in previous studies, and the overall migratory pattern was similar to published reports (Rajasekariah et al. 1985; Behnke et al. $1986 b)$.

The tissue-specific feeding levels of larvae recovered at 66,72 , and $90 \mathrm{~h} \mathrm{p}$.i. were compared (Fig. 2 ). There was no significant difference between the percentage of feeding larvae recovered from the lungs when compared to larvae recovered from the skin, indicating that the decline in feeding resulted from an overall decrease in feeding, and not from decreased feeding by a particular tissue-associated developmental group.

\section{Discussion}

Although the biology of the free-living and adult stages of hookworms has been extensively studied, little is known about the biology of the parasitic larval stages (Hoagland \& Schad, 1978). Most investigations of this portion of hookworm lifehistory have concentrated on the migratory behaviour of larvae within the host. However, physiological, biochemical and molecular aspects of infecting and developing stages remain poorly understood, due largely to the technical difficulties in recovering sufficient numbers for such studies, and the inability to culture hookworm larvae beyond the $\mathrm{L}_{3}$ in vitro. For example, the host signal that reactivates development in the invading $\mathrm{L}_{3}$ is poorly characterized. In order to investigate the early events of the infectious process, including the mechanism of developmental re-activation, Hawdon \& Schad (1990) proposed the resumption of feeding as a marker for the re-activation of development, and developed an in vitro assay to measure feeding by $A$. caninum $\mathrm{L}_{3}$. Subsequent experiments indicated that albumin (Hawdon \& Schad, 1991b) and glutathione (Hawdon \& Schad, 1992) stimulated feeding, and that in vitro feeding occurred in most species of hookworms examined, including $A$, duodenale and A. ceylanicum (Hawdon et al. 1992). The experiments presented here were conducted to determine the role of feeding by parasite $\mathrm{L}_{3}$ in the life-history of the hookworm.

A. caninum $\mathrm{L}_{3}$ recovered from the small intestine of orally infected dogs were feeding at very low levels. Furthermore, orally inoculated $A$. ceylanicum larvae failed to feed until after moulting to the $\mathrm{L}_{4}$. One possible explanation for the lack of feeding larvae is that only non-feeding larvae were sufficiently motile to be recovered by the techniques employed. However, in most cases sufficient numbers of larvae were recovered to ensure against selection for non-feeding larvae. Another possibility is that feeding was depressed by removal of the 
larvae from the host for extended times during the isolation and feeding procedure. However, all incubations during recovery were under host-like conditions $\left(37^{\circ} \mathrm{C}, 5 \% \mathrm{CO}_{2}\right)$, which are employed for in vitro feeding studies (Hawdon \& Schad, 1990). Once $\mathrm{L}_{3}$ have begun to feed in vitro, they continue to feed for a minimum of $3 \mathrm{~h}$ after removal from the incubation conditions. It is unlikely that further incubation after removal from the host would decrease feeding. Furthermore, larvae that were feeding, such as $A$. ceylanicum and $N$. americanus $\mathbf{L}_{3}$ isolated from skin, were subjected to similar conditions. It is more likely that few of the Ancylostoma spp. $\mathrm{L}_{3}$ feed after infection per os.

Despite the primacy of the oral route for A. caninum (Wilson, 1982) and A. ceylanicum infection (Gupta et al. 1987), $\mathrm{L}_{3}$ of these species can also infect their hosts via the percutaneous route (Yoshida, Okamoto \& Chiu, 1971; Behnke, 1990). Therefore, feeding behaviour of $\mathrm{L}_{3}$ isolated from the skin was examined. The A. ceylanicum-hamster model was utilized because of the expense and logistical difficulties of recovering larvae from dogs. The time-dependent increase in feeding by $\mathrm{L}_{3}$ recovered from the skin of hamsters indicated that feeding occurred in A. ceylanicum parasitic $\mathrm{L}_{3}$ when the larvae entered via the skin.

Apparently, the facultative skin-penetrating hookworms, such as A. ceylanicum and A. caninum, employ different feeding behaviours depending on their route of entry. One possible explanation for this difference in feeding behaviour is that feeding provides nutrients to meet the energetic demands of migration. In order to reach the intestine, $\mathrm{L}_{3}$ that enter through the skin must undergo tissue migration, which requires both time and energy expenditure. Indeed, larval development was slower in percutaneous infections than in oral infections, as A. ceylanicum $\mathrm{L}_{3}$ remained in the skin for $44 \mathrm{~h}$ without migration or obvious morphological development. Skin-penetrating $\mathrm{L}_{3}$ would be exposed to GSH and the phagostimulant(s) present in serum during this skin phase and the subsequent migration, whereas $\mathrm{L}_{3}$ that enter orally would not be exposed to stimulatory levels of the phagostimulants.

However, feeding is not required for development to resume, as larvae that entered orally resumed development without feeding as $\mathrm{L}_{3}$. This suggests that the feeding stimulus is independent from the stimulus that re-initiates development. The developmental stimulus is present in the host's intestine, but if this signal is specific to the predilection site, then migrating larvae, although feeding, would not be developing. Once they reach the small intestine, they would be exposed to the second stimulus, and development would resume. Alternatively, if the developmental stimulus was present throughout the host, feeding would indicate that the larvae had resumed development. However, if the feeding stimulus is restricted to parenteral locations, $\mathrm{L}_{3}$ entering orally would not feed, despite having resumed development. Feeding, therefore, is not mandatory for development, but larvae that have resumed feeding are probably also developing. Considerably more work is required to clarify this interesting situation, which apparently has not been investigated previously by parasitologists and others interested in nematode development.

Although the role of feeding in the life-history of the Ancylostoma spp. is uncertain, the results of in vivo experiments indicate that feeding by parasitic $\mathrm{L}_{3}$ is an important facet of the life-history of $N$. americanus. Feeding resumed shortly after entry into the host, and continued while the larvae were in the skin, but decreased as the larvae migrated to the lungs from $48-90 \mathrm{~h} \mathrm{p.i.} \mathrm{This} \mathrm{decrease} \mathrm{in} \mathrm{feeding} \mathrm{was}$ a programmed response, and not merely the result of changing locations, as there was no significant difference $(P>0.05)$ in feeding between $\mathrm{L}_{3}$ isolated from the skin and lungs at any time-point of the migration. By $120 \mathrm{~h}$, over $98 \%$ of the larvae had reached the lungs, and feeding had decreased to approximately $30 \%$. Feeding resumed following the moult to the $\mathrm{L}_{4}$.

$N$. americanus is an obligate skin-penetrating hookworm, and larvae cannot establish in the intestine when inoculated orally (Komiya \& Yasuraoka, 1966; Hoagland \& Schad, 1978; Behnke et al. $1986 a$ ), unless they succeed in penetrating the oral mucosa (Nagahana et al. 1962). Traditionally, this has been interpreted as indicating the requirement of an obligatory lung migration for development to continue (Komiya \& Yasuraoka, 1966; Hoagland \& Schad, 1978), and morphological development during the long period of residence in the lungs (Sen \& Seth, 1979; Behnke et al. $1986 a$ ) further supports an obligatory lung phase. However, $N$. americanus $\mathrm{L}_{3}$ remained in the skin for $48-72 \mathrm{~h}$ p.i. (Behnke et al. $1986 a$ ), during which time their motility decreased (Ishikawa, 1966). This period in the skin may be required to re-activate developmental pathways and initiate expression of genes required for the parasitic stages (Rogers \& Petronijevic, 1982). Indeed, the results presented indicate that one event occurring during this skin phase is the re-activation of larval feeding. Therefore, the host stimulus that induces feeding is present in the skin, and encountered by the larvae during infection. However, it is possible that there is a second signal, present in the lungs, that actually leads to the re-activation of developmental pathways, and that feeding is not invariably linked to development. Although direct evidence is absent, results argue against this suggestion. The decline in $N$. americanus $\mathrm{L}_{3}$ feeding between 48 and $120 \mathrm{~h}$ probably represents the onset of the lethargus prior to the $\mathrm{L}_{3}-\mathrm{L}_{4}$ moult. The onset of a programmed decrease in feeding, or lethargus, prior to arrival in the lungs suggests that devel- 
opmental pathways were re-activated in the skin and, therefore, feeding by $\mathrm{L}_{3}$ indicates that development has resumed.

Although feeding by parasitic $\mathrm{L}_{3}$ is an important event during $N$. americanus infections, attempts to induce similar feeding in vitro have been unsuccessful, indicating that the in vitro feeding system lacks the host signal that initiates feeding and development of $N$. americanus $\mathrm{L}_{3}$ in vivo. The nature of this signal remains unknown. Salafsky et al. (1990) found that linoleic acid stimulated penetration of artificial membranes and triggered the production of eicosanoids, but linoleic acid failed to stimulate feeding in vitro (Hawdon et al. 1992). The requirement for separate signals to initiate penetration and feeding supports the hypothesis (Matthews, 1977) that the infectious process is composed of distinct steps, including penetration, exsheathment and the re-activation of development and feeding, that are initiated by independent factors encountered in the host, and required in sequence for successful development to the adult stage.

The authors would like to thank Cindy Xanthopoulos for technical assistance in maintaining the parasites, and Robert Rew, George Conder, Jay Farrell, James Lok and Peter Hotez for critical reviews of the manuscript. This work was supported in part by NIH Grant 5RO1-AI22662, BRSG 507RRB5464, and NATO Collaborative Research Grant 880450 . Stipend support for J.M.H. was provided by Upjohn Laboratories.

\section{REFERENCES}

BANERJEe, D., PRAKash, o. \& DEO, M. G. (1970). Studies on Ancylostoma caninum infection in mice following percutaneous and intraperitoneal routes of infection. Indian fournal of Medical Research 58, 1313-20.

BEHNKE, J. M. (1990). Laboratory animal models. In Hookworm Disease : Current Status and New Directions (ed. Schad, G. A. \& Warren, K. S.), pp. 105-28. London: Taylor and Francis.

BEHNKE, J. M. \& PRITCHARD, D. I. (1987). Necator americanus in neonatally infected hamsters. The timecourse of infection and antibody response to the surface antigens of $\mathrm{L}_{4}$ and adult worms. Transactions of the Royal Society of Tropical Medicine and Hygiene 81, 967-72.

BEHNKE, J. M., PAUL, v. \& RAJASEKARIAH, G. R. (1986a).

The growth and migration of Necator americanus following infection of neonatal hamsters. Transactions of the Royal Society of Tropical Medicine and Hygiene 80, 146-9.

BEHNKE, J. M., WELL.S, C. \& BROWN, J. (1986 b). An improved technique for experimental infections with skin-penetrating nematode larvae (Necator americanus). International fournal for Parasitology 16, 461-4.

BHOPALE, M. K. \& JOHRI, G. N. (1975). Experimental infection of Ancylostoma caninum in mice. II. Migration and distribution of larvae in tissues after oral infection. Fournal of Helminthology 49, 179-85.
FOSTER, A. O. \& CROSS, S. x. (1934). The direct development of hookworms after oral infection. American Journal of Tropical Medicine 14, 565-73. Garside, P. \& BEHNKE, J. M. (1989). Ancylostoma ceylanicum in the hamster: observations on the host-parasite relationship during primary infection. Parasitology 98, 283-9.

GUPTA, S., SRIVASTAVA, J. K. \& KatiyaR, J. c. (1987). Ancylostoma ceylanicum: migratory behaviour in golden hamsters after oral and parenteral infection. Annals of Tropical Medicine and Parasitology 81, 421-8.

HAWDON, J. M. \& SCHAD, G. A. (1990). Serum-stimulated feeding in vitro by third-stage infective larvae of the canine hookworm Ancylostoma caninum. Fournal of Parasitology 76, 394-8.

HAWDON, J. M. \& SCHAD, G. A. (1991 a). Long-term storage of hookworm infective larvae in buffered saline solution maintains larval responsiveness to host signals. Fournal of the Helminthological Society of Washington 58, 140-2.

HAWDON, J. M. \& SCHAD, G. A. $(1991 b)$. Albumin and a dialyzable serum factor stimulate feeding in vitro by third-stage larvae of the canine hookworm Ancylostoma caninum. Journal of Parasitology 77, 587-91.

haWDON, J. M. \& SCHAD, G. A. (1992). Ancylostoma caninum: reduced glutathione stimulates feeding by third-stage infective larvae. Experimental Parasitology 75, 40-6.

HAWDON, J. M., VOLK, S. W., PRITCHARD, D. I. \& SCHAD, G. A. (1992). Resumption of feeding in vitro by hookworm third-stage larvae: a comparative study. Fournal of Parasitology (in the Press.)

HOAGLAND, K. E. \& SCHAD, G. A. (1978). Necator americanus and Ancylostoma duodenale: life history parameters and epidemiological implications of two sympatric hookworms of humans. Experimental Parasitology 44, 36-39.

ISHIKAWA, M. (1966). Studies on the behaviour of the third-stage larvae of Necator americanus in the skin of the host and its biological significance. Fournal of the Kyoto Prefecture Medical University 75, 883-98. (In Japanese.)

KOMIYA, Y. \& YASLRAOKA, K. (1966). The biology of hookworms. In Progress of Medical Parasitology in Japan (ed. Morishita, K., Komiya, Y. \&

Matsubayashi, H.), pp. 5-114. Tokyo: Meguro Parasitological Museum.

Matтhews, в. Е. (1977). The passage of larval helminths through tissue barriers. In Parasite Invasion. Symposia of the British Society for Parasitology (ed. Taylor, A. E. R. \& Muller, R.), pp. 93-119. London: Blackwell Scientific Publications.

MILLER, T. A. (1971). Vaccination against canine hookworm disease. Advances in Parasitology 9, 153-83.

NAGAHANA, M., Yoshida, Y., TANABE, K., KONDO, K., OKAMOTO, K., OKADA, S., SATO, K., ITO, S., FUKUTOME, s. \& Ishikawa, M. (1962). Experimental studies on the oral infection of Necator americanus. II. The infection of puppies with $N$. americanus larvae through the mucous membrane of the mouth. Japanese fournal of Parasitology 11, 488-98. (In Japanese.) 
RAJASEKARIAH, G. R., DEB, B. N., DHAGE, K. R. \& BOSE, S. (1985). Site of resistance to Necator americanus in hamsters. Acta Tropica 42, 333-40.

RAY, D. K. \& BHOPALE, K. K. (1972). Complete development of Ancylostoma ceylanicum (Looss, 1911) in golden hamsters, Mesocricetus auratus. Experientia 28, 359-60.

ROgERs, W. P. \& PETRONIJEVIC, T. (1982). The infective stage and the development of nematodes. In Biology and Control of Endoparasites (ed. Symons, L. E. A., Donald, A. D. \& Dineen, J. K.), pp. 3-28. Sydney: Academic Press.

SAlAFSKY, B., FUSCO, A. C. \& SIDDIQLi, A. (1990). Necator americanus: factors influencing skin penetration by larvae. In Hookworm Disease : Current Status and New Directions (ed. Schad, G. A. \& Warren, K. S.), pp. 329-39. London: Taylor \& Francis.

SCHAD, G. A. (1979). Ancylostoma duodenale: maintenance through six generations in helminth-naive pups. Experimental Parasitology 47, 246-53.

SCHAD, G. A. (1982). Arrested development of Ancylostoma caninum in dogs: influence of photoperiod and temperature on induction of a potential to arrest. In Aspects of Parasitology : a Festschrift Dedicated to the Fiftieth Anniversary of the Institute of Parasitology of McGill University (ed. Meerovitch, E.), pp. 361-91. Montreal: McGill University.

scotT, J. A. (1930). The biology of hookworms in their hosts. Quarterly Review of Biology 5, 79-97.

SEN, H. G. (1972). Necator americanus: behaviour in hamsters. Experimental Parasitology 32, 26-32.

SEN, H. G. \& SETH, D. (1970). Development of Necator americanus in golden hamsters, Mesocricetus auratus. Indian Fournal of Medical Research 58, 1356-60.

WILSON, P. A. G. (1982). Roundworm juvenile migration in mammals: the pathways of skin penetrators reconsidered. In Aspects of Parasitology : a Festschrift Dedicated to the Fiftieth Anniversary of the Institute of Parasitology of McGill University (ed. Meerovitch, E.), pp. 461-85. Montreal: McGill University. yoshidA, Y., OKAMoto, K. \& CHIU, J. K. (1971). Experimental infection of man with Ancylostoma ceylanicum Looss, 1911. Chinese Fournal of Microbiology 4, 157-67. 